\title{
CONCRETO AUTOCICATRIZANTE: ANÁLISE COMPARATIVA DA REGENERAÇÃO EM AMOSTRAS COM DIFERENTES TEORES DE PERLITA ENCAPSULADAS COM SILICATO DE SÓDIO
}

\author{
SELF-HEALING CONCRETE: COMPARATIVE ANALYSIS OF REGENERATION IN SAMPLES \\ WITH DIFFERENTE CONTENTS OF PERLITE ENCAPSULATED WITH SODIUM SILICATE
}

\author{
MENDEZ, BRUNO MATHEUS GABE \\ Acadêmico de Engenharia Civil \\ UNISINOS/Itt Performance \\ São Leopoldo/RS; Brasil \\ brunomgmendez@hotmail.com
}

\author{
DONADELLO, MATHEUS \\ Acadêmico de Engenharia Civil \\ UNISINOS/Itt Performance \\ São Leopoldo/RS; Brasil \\ mdonadello@unisinos.br
}

\author{
EHRENBRING, HINOEL ZAMIS \\ Prof. MSc. Engenheiro Civil \\ UNISINOS/Itt Performance \\ São Leopoldo/RS; Brasil \\ hzamis@unisinos.br
}

\author{
MOREIRA, GIAN DE FRAGA \\ Acadêmico de Engenharia Civil \\ UNISINOS/Itt Performance \\ São Leopoldo/RS; Brasil \\ gianfm@unisinos.br
}

\author{
PACHECO, FERNANDA \\ Prof. MSc. Engenheira Civil \\ UNISINOS/Itt Performance \\ São Leopoldo/RS; Brasil \\ fernandapache@unisinos.br
}

\author{
TUTIKIAN, BERNARDO FONSECA \\ Prof. DSc. Engenheira Civil \\ UNISINOS/Itt Performance \\ São Leopoldo/RS; Brasil \\ bftutikian@unisinos.br
}

\section{RESUMO}

A durabilidade do concreto armado é um tópico frequentemente abordado dada a sua importância para que o sistema mantenha sua capacidade portante e sustentabilidade. Outro motivo a ser destacado é a necessidade de redução de custos com restaurações, reparos ou substituições. Estudos apresentados nos últimos anos visam desenvolver um novo tipo de concreto que tem a característica de autocicatrização, ou seja, atua reparando suas próprias fissuras, e por consequência, aumentando sua durabilidade e sustentabilidade. Um dos métodos de regeneração consiste na adição de soluções químicas como aditivos cristalizantes e minerais. Tais materiais, ao reagir com a água que penetra nas fissuras, tem a capacidade de gerar cristais, colmatando esses vazios. Sendo assim, este artigo científico tem como objetivo avaliar o potencial de regeneração e a resistência à compressão de uma composição de concreto, no qual adicionou-se silicato de sódio neutro encapsulado em agregados de perlita expandida. O agregado leve foi empregado em substituição a areia nos percentuais de 10\% (T10) e 20\% (T20). A incorporação de perlitas contendo silicato de sódio neutro ocasionou, na resistência à compressão, um aumento de aproximadamente $2 \%$ da mistura T10 em relação a amostra sem substituição (T0 - cimento, areia e brita) aos 28 dias. Com o teor de uso de $20 \%$ esse ganho foi de $4,8 \%$, aproximadamente. Em termos de cicatrização ambas amostras mantiveram um padrão, entretanto, a mistura T20 apresentou um melhor desempenho.

Palavras-chave: concreto, durabilidade, fissuras, autocicatrização.

\section{ABSTRACT}

The durability of reinforced concrete is a topic frequently addressed due to its importance for the system to maintain its bearing capacity and sustainability over time. In addition, there is a demand to reduce costs with restorations, or replaces in structures. Studies presented in recent years aim to develop a new type of concrete that has the characteristic of self-healing, that is, it acts by repairing its own cracks, and consequently, increasing its durability and sustainability. One of the regeneration methods consists of adding chemical solutions such as crystallizing and mineral additives. Such materials, by reacting with the water that penetrates the cracks, have the ability to generate crystals that heal it. Thus, this scientific article aims to evaluate the regeneration potential and the compressive strength of a concrete mix, in which neutral sodium silicate encapsulated in expanded perlite aggregates was added. The lightweight aggregate was 
used to replace sand in the percentages of $10 \%$ (T10) and 20\% (T20). The incorporation of perlites containing neutral sodium silicate caused, in the compressive strength, an increase of approximately $2 \%$ of the T10 mix in relation to the sample without substitution (T0 - cement, sand and gravel) at 28 days. With the $20 \%$ usage content, this gain was approximately $4,8 \%$. In terms of healing, both samples maintained a pattern, however, the T20 mixture showed a better performance.

Keywords: concrete, durability, cracks, self-healing.

\section{INTRODUÇÃO}

O concreto é um material que possibilitou o aperfeiçoamento de obras ao longo da história. Sem dúvidas no campo dos estudos ainda há muitas possibilidades de desenvolvimento. Uma das características fundamentais do concreto é a durabilidade que pode ser definida como a exposição do material a uma condição específica por um determinado tempo, garantindo sua utilização, respeitando o especificado em projeto para sua vida útil. (FARAH, 2018). Segundo a NBR 6118 (ABNT, 2014), o concreto se deteriora em função do meio ambiente no qual está inserido devido a fatores físicos e químicos, e isso não depende de ações mecânicas como esforços, de variações volumétricas devido a possíveis gradientes térmicos, retrações hidráulicas e outras que podem ser previstas no dimensionamento deste tipo de estrutura.

Uma das manifestações patológicas de ocorrência mais expressiva nas estruturas de concreto armado é a fissuração. O surgimento de uma fissura facilita a entrada de agentes agressores, afetando a durabilidade do elemento (CLAUDINO et al., 2017). Fissuras são consequências de mecanismos que atuam sob os materiais, ocorrendo de modo a aliviar tensões que lhe são impostas. As fissuras em elementos expostos a intempéries ocorrem geralmente devido à incompatibilidade do material com o ambiente no qual está inserido. Além deste, a incompatibilidade do processo construtivo, a velocidade de execução ou até a falta de um projeto que considere sobrecargas iminentes as estruturas, por exemplo, podem ser motivos fundamentais para que surjam estes tipos de deformações (VIEIRA, 2008).

Dentre os setores chave para a sustentabilidade ambiental, tem-se a construção civil, que é uma das maiores geradoras de impactos ambientais negativos ligados, principalmente, a matéria prima, transporte de materiais, ruídos, impermeabilização do solo ou inclusive na geração de resíduos da construção e demolição. Visto a magnitude de impactos prejudiciais ao meio ambiente causados pela utilização de materiais com base de cimento Portland, a durabilidade do concreto armado é um tópico muito abordado, (SBARDELOTTO et al., 2019).

Diferentes estudos vêm sido desenvolvidos abordando o concreto que consiga autorreparar suas fissuras. Na década de 1990, surgiram os primeiros experimentos com características como essa em materiais à base de cimento, desde esta época, pesquisadores estudam o tema com o intuito de aprofundar o conhecimento sobre o mecanismo e difundir seu uso. A autocicatrização pode ser definida como a recuperação do material, devolvendo sua característica superficial inicial e mantendo sua proteção a ação de danos. Os materiais cicatrizantes estão inseridos em uma categoria de estruturas inteligentes, pois trabalham de maneira autônoma liberando agentes de cicatrização quando as fissuras ocorrem, aumentando sua vida funcional (MOREIRA, 2016).

Tal característica do concreto pode representar uma economia de custos diretos, relacionados à manutenção e reparo da estrutura, e de custos indiretos, visto que estas estruturas necessitam ficar em desuso durante a manutenção. Também, os materiais autocicatrizantes têm aplicação no reparo de concreto em lugares de difícil acesso para realizar a manutenção, como por exemplo, em instalações de resíduos nucleares, em tomadas d’água de barragens e laje de subpressão (TAKAGI, 2013).

Alguns fatores podem influenciar na capacidade de cicatrização do concreto, dentre eles, a composição do concreto em relação aos materiais empregados na sua confecção, relação água/cimento, quantidades de agregados utilizados, o grau do dano a estrutura, a idade em que a primeira fissura ocorreu, condições de umidade relativa, período e tipo de cura, entre outros (VENQUIARUTO, 2017).

Para um dos pioneiros nos estudos sobre este tipo de material, Henk Jonkers da Universidade Técnica de Delft, a autocicatrização não possuirá uma dimensão máxima para regeneração das fissuras em relação a sua extensão mas sim pela sua abertura que segundo ele, não pode ter mais que $8 \mathrm{~mm}$. Jonkers comenta também que por mais que o custo deste concreto autocicatrizante seja maior que o concreto convencional, ainda sim poderá existir uma vantagem econômica considerando que custos de manutenção são economizados (DE ARAUJO, 2019). 
As tipologias de cicatrização podem ser divididas de maneira mais simples em dois grandes grupos: cicatrização autógena e cicatrização autônoma. No primeiro grupo, a regeneração ocorre de maneira natural, ou seja, os processos de autocura ocorrem pelos materiais corriqueiramente empregados no concreto (cimento e adições pozolânicas), enquanto isso, no sistema autônomo, há a utilização de maneiras especificamente para proporcionar a recuperação das fissuras (soluções químicas, biológicas, materiais com memória de forma, polímeros super absorventes, aditivos cristalizantes, entre outros), (BIANCHIN, 2018).

Concretos autocicatrizantes podem ser desenvolvidos com a inserção de aditivos químicos combinados com alto teor de finos, podendo ser adições minerais, fillers, ou até a substituição de cimentos puros por cimentos compostos. Atualmente há a busca pela utilização de produtos comerciais com essa finalidade, facilitando a execução da estrutura (CAPPELLESSO, 2018).

Um dos métodos de regeneração consiste na adição de soluções químicas como aditivos cristalizantes e minerais. O silicato de sódio $\left(\mathrm{Na}_{2} \mathrm{SiO}_{3}\right)$ é um composto que pode ser utilizado para prevenir corrosão biogênica de elementos de concreto causados por ácido sulfúrico $\left(\mathrm{H}_{2} \mathrm{SO}_{4}\right)$, que pode ser resultado, por exemplo, de reações em estações de tratamento de esgoto. De uma forma geral o silicato de sódio neutro auxilia na cicatrização das fissuras, reduzindo a permeabilidade da matriz, pelo processo de combinação química no qual há formação de C-S-H na matriz cimentícia (DOBROVOLSKI et al., 2019). Considerando o uso de produtos químicos, discute-se a maneira mais eficaz de utilização desse material, sejam imersos em agregados leves, polímeros superabsorventes, ou ainda, lançados diretamente juntamente com a água de amassamento. Zhang et al (2017) destacaram que há vantagens no uso de perlita expandida como agregado leve para encapsulamento de soluções químicas ou biológicas.

Sendo assim, este artigo científico tem como objetivo avaliar o potencial de regeneração e a resistência à compressão de uma composição de concreto no qual adicionou-se silicato de sódio neutro, em diferentes percentuais, encapsulado em perlitas expandidas, adicionadas em substituição de areia relacionada a massa com compensação em volume nos percentuais de $10 \%$ (T10) e $20 \%$ (T20).

\section{PROGRAMA EXPERIMENTAL}

Para o programa experimental conduzido, realizou-se as seguintes etapas: inicialmente foi escolhido o traço referência (T0) para o concreto em estudo, no qual adotou-se as substituições do agregado miúdo pelo agregado leve (perlita expandida). Após, partindo-se desse, foram desenvolvidos outros dois, substituindo neles a areia pela perlita nos percentuais de $10 \%$ (T10) e 20\% (T20) em massa com compensação do volume A relação água/cimento manteve-se a mesma para ambas as misturas. Após a determinação dos traços, foram caracterizados os agregados utilizados, seguindo minuciosamente a norma ABNT NBR NM 248. Para a verificação do concreto no estado endurecido, foram realizados os ensaios de resistência a compressão axial aos 7 e 28 dias em corpos de prova com dimensões de 10 x $20 \mathrm{~cm}$, bem como mapeamento das fissuras que foram induzidas aos 28 dias, em corpos de prova prismáticos com dimensões de $6 \mathrm{x}$ $6 \times 18 \mathrm{~cm}$, onde as fissuras foram induzidas utilizando uma prensa universal de ensaios, em ensaio de tração na flexão, com carga máxima de $12 \mathrm{kN}$. A Figura 1 apresenta o fluxograma do programa experimental.

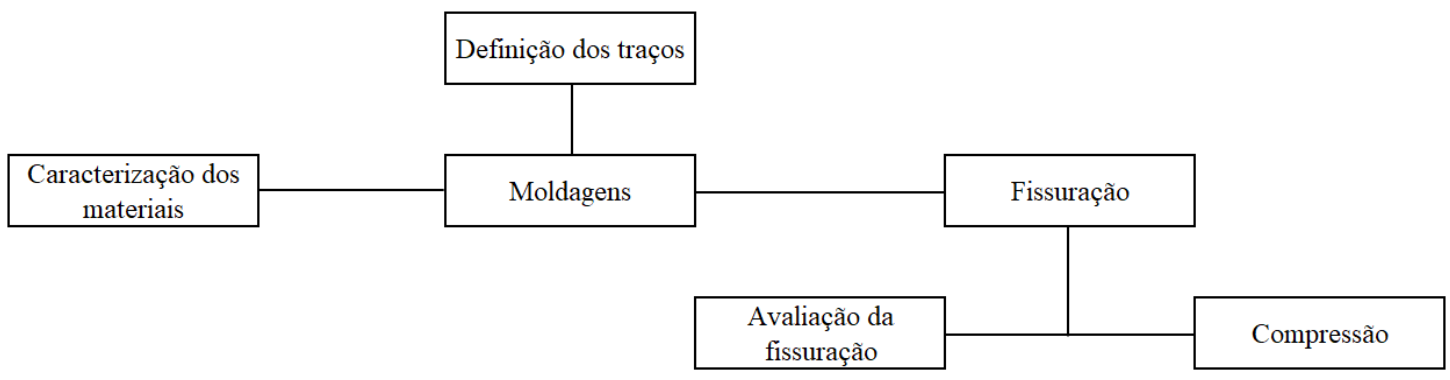

Fonte: Elaborado pelo autor.

Figura 1 - Fluxograma do programa experimental

\subsection{Materiais}

Para a confecção do concreto, foram utilizados os seguintes materiais: Cimento Portland tipo II - F, agregados miúdo e graúdo, sendo areia quartzosa e brita basáltica. Para encapsulamento das soluções químicas utilizou-se perlita expandida. Os materiais foram caracterizados seguindo as normas correspondentes. 


\subsection{Caracterização dos agregados}

A caracterização foi realizada seguindo as diretrizes da ABNT NBR NM 248:2003. Também, foi utilizada a ABNT NBR NM 52 para agregado miúdo e ABNT NBR NM 53 para agregado graúdo. Na Tabela 1, são apresentados os resultados obtidos da caracterização do agregado miúdo bem como da perlita e do agregado graúdo (Brita 0 ).

Tabela 1 - Caracterização física dos agregados

\begin{tabular}{|c|c|c|c|}
\hline \multicolumn{4}{|c|}{ Massa específica (NBR NM 52:2009) } \\
\hline & Areia Média & Perlita & Brita 0 \\
\hline Agregado seco $\left(\mathrm{g} / \mathrm{cm}^{3}\right)$ & 2,52 & - & 3,08 \\
\hline Saturada superfície seca $\left(\mathrm{g} / \mathrm{cm}^{3}\right)$ & 2,59 & - & 2,88 \\
\hline Massa específica $\left(\mathrm{g} / \mathrm{cm}^{3}\right)$ & 2,70 & 0,94 & 2,79 \\
\hline Absorção (\%) & - & - & 3,41 \\
\hline \multicolumn{4}{|c|}{ Análise granulométrica (NBR NM 248:2003) } \\
\hline & Areia média & Perlita & Brita 0 \\
\hline Dimensão máxima característica & 2,36 & 4,75 & 12,5 \\
\hline Módulo de finura & 3,01 & 4,14 & 2,86 \\
\hline
\end{tabular}

Fonte: Elaborado pelo autor.

\subsection{Composição dos traços}

Para este estudo, foram realizados 3 composições de concreto (T0, T10 e T20), que possuem a mesma relação água/cimento e quantidade unitária de aglomerante e agregado graúdo, sendo assim, variando a quantidade apenas do agregado miúdo, onde nesse, a perlita substitui percentualmente a quantidade em volume da areia para a mistura T10 e T20. A Tabela 2, apresenta a identificação das amostras, e suas respectivas composições.

Tabela 2 - Identificação das amostras e composição referente

\begin{tabular}{cccc}
\hline \multirow{2}{*}{ Material } & \multicolumn{3}{c}{ Traços (Unitário) } \\
\cline { 2 - 4 } & T0 & T10 & T20 \\
\hline Cimento & 1,00 & 1,00 & 1,00 \\
\hline Agregado Miúdo & 3,20 & 2,88 & 2,56 \\
\hline Agregado Graúdo & 3,17 & 3,17 & 3,17 \\
\hline Perlita Expandida & 0 & $10 \%$ & $20 \%$ \\
\hline Água/Cimento & & 0,60 \\
\hline
\end{tabular}

Fonte: Elaborado pelo autor.

\subsection{Ensaios}

2.3.1 Resistência à compressão de corpos de prova cilíndricos de concreto A resistência à compressão foi determinada através da ABNT NBR 5739 (2018). Os corpos de prova 10x20cm, foram armazenados em sala com temperatura de $23 \pm 2{ }^{\circ} \mathrm{C}$ e umidade de $95 \%$, após 24 horas de sua moldagem. As amostras foram retificadas, sendo 3 amostras de cada mistura, com duas diferentes idades, 7 e 28 dias.

\subsubsection{Mapeamento das fissuras induzidas através do ensaio de tração na flexão 3 pontos}

Para identificar a autocicatrização das amostras, foi realizado a indução de microfissuras, através do ensaio de tração na flexão por 3 pontos segunda a ABNT NBR 12142 (2010). A Figura 2 ilustra o ensaio e as fissuras gerada pelo mesmo, o ensaio foi realizado após os 28 dias de cura das amostras, em câmara padronizada, então, após fissuradas, as amostras ficaram em repouso mais 28 dias na mesma câmara, quando então, foi realizada a análise microscópica. O parâmetro utilizado para o ensaio de tração na flexão foi a verificação de microfissuras das quais poderiam, posteriormente, ser avaliadas a sua cicatrização. Desta forma, todas as amostras foram carregadas até $12 \mathrm{kN}$ de carga, onde já apresentavam as fissuras esperadas sem danificar demasiadamente as amostras. 

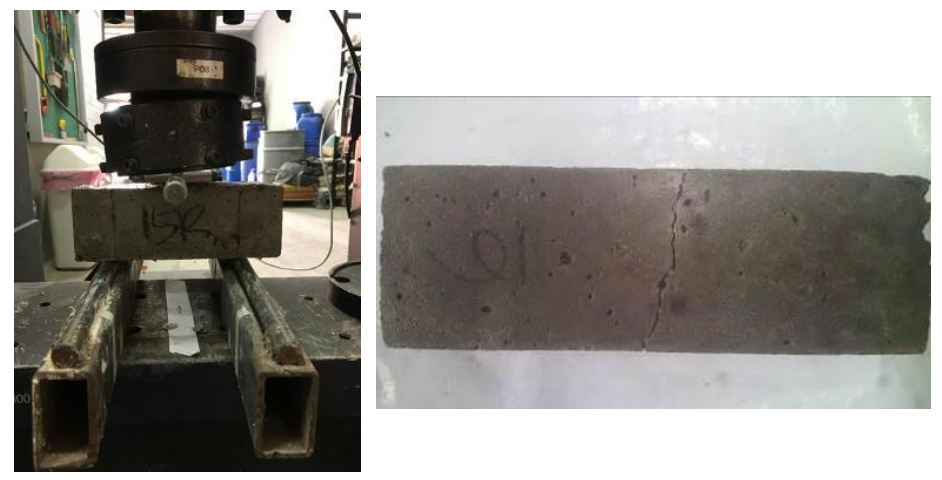

Fonte: Acervo do autor.

Figura 2 - Ensaio de tração na flexão e fissura gerada

\section{RESULTADOS}

\subsection{Resistência à compressão}

A Tabela 3 apresenta os resultados de resistência à compressão das amostras e a média de cada composição por idade.

Tabela 3 - Resultados de resistência à compressão

\begin{tabular}{c|cc|cc}
\hline \multirow{2}{*}{ Traço } & \multicolumn{4}{|c}{ Resistência à compressão (MPa) } \\
\cline { 2 - 5 } & \multicolumn{4}{|c}{ Idade } \\
\cline { 2 - 5 } & Média (MPa) & Desvio Padrão Amostral & Média (MPa) & Desvio Padrão Amostral \\
\cline { 2 - 5 } T0 & 31 & 3,9 & 34,2 & 5,7 \\
\hline T10 & 30 & 0,5 & 34,8 & 1 \\
\hline T20 & 31,5 & 1,3 & 35,8 & 1,1 \\
\hline
\end{tabular}

Fonte: Elaborado pelo autor.

Analisando os dados encontrados acima percebe-se que para a idade de 7 dias as amostras apresentaram pouca variação de resistência nas diferentes tipologias de substituição com perlita. Entretanto, para a idade de 28 dias, as amostras demonstraram uma alteração, ainda que de pequeno valor, mais expressiva, sendo essa 1,6 MPa em média, da amostra T0 para a amostra T20. Este aumento de resistência foi gradativo e diretamente proporcional a quantidade de substituição de perlita nas amostras, ou seja, localizando a mistura T1 entre as duas citadas anteriormente.

Segundo Khonsari et al. (2010) existe uma relação inversamente proporcional entre a resistência mecânica e o uso da perlita expandida. Em seus estudos comparando uma amostra referência, sem nenhuma substituição, e amostras com $15 \%$ e $20 \%$ de substituição em perlita, a perda de resistência em percentual foi de aproximadamente $24 \%$ e $40 \%$, respectivamente.

Jondidi, Renjeddou e Soussi (2015) ainda complementam estes dados dizendo que a resistência recebe uma mudança mais expressiva em valores de substituição maiores que 45\%. Vergara et al. (2019) confirma o citado anteriormente quando conclui que a substituição de perlita pelos agregados finos em teores superiores a $40 \%$ apresentam valores de resistência a compressão mais evidentes e conclusivos. $\mathrm{O}$ mesmo ainda cita que a repercussão sofrida na matriz pela incorporação de perlita expandida varia de acordo com a distribuição granulométrica e o módulo de finura da composição.

Os resultados encontrados neste estudo mostram que, diferente do encontrado por outros autores utilizando perlita expandida, a resistência tende a aumentar e não diminuir de acordo com o uso da perlita. Com mais perlita há mais silicato e assim as propriedades de cicatrização do concreto melhoram, por consequência, as amostras podem recuperar suas propriedades mecânicas visto que a cicatrização não ocorre somente nas fissuras, mas também nos poros do concreto. Contudo, deve se considerar que este estudo avaliou misturas com substituição em um valor máximo de $20 \%$, valor menor ao qual a diferença de resistência se torna realmente evidente. Considerando este ponto, através dos dados, pode-se concluir que o material possui um grande potencial de uso, pois possui maior quantidade de materiais autocicatrizantes e ainda possui uma resistência a compressão maior, ou seja, apresentará fissuras com menor facilidade e menores dimensões (principalmente com menor espessura da fissura), o que potencializa a cicatrização. 


\subsection{Cicatrização das fissuras}

A Figura 3 demonstra a autocicatrização das amostras T0, a Figura 4 das amostras T10 e a Figura 5 das amostras T20. Estas análises foram realizadas transcorridos 28 dias do dia em que as amostras foram fissuradas, tendo sido mantidas em câmara com temperatura de $23 \pm 2^{\circ}$ e umidade relativa acima de $95 \%$.
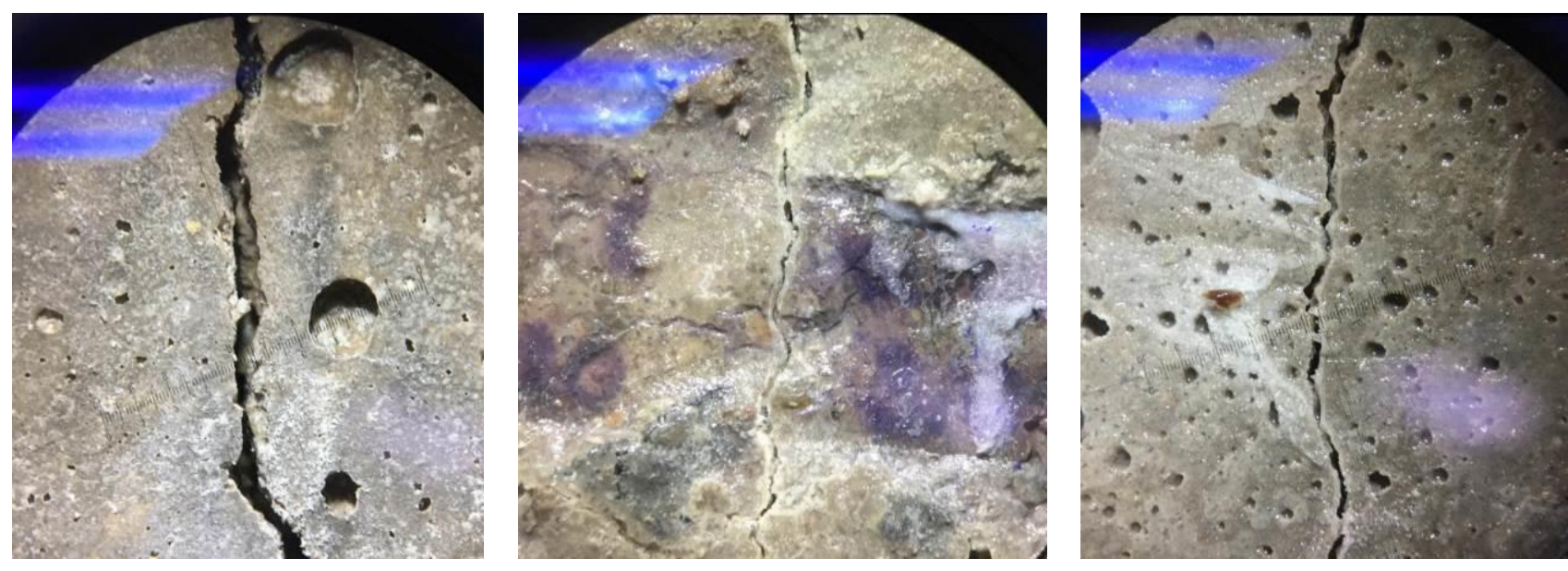

Fonte: Acervo do autor.

Figura 3 - Análise microscópica da autocicatrização nas amostras T0
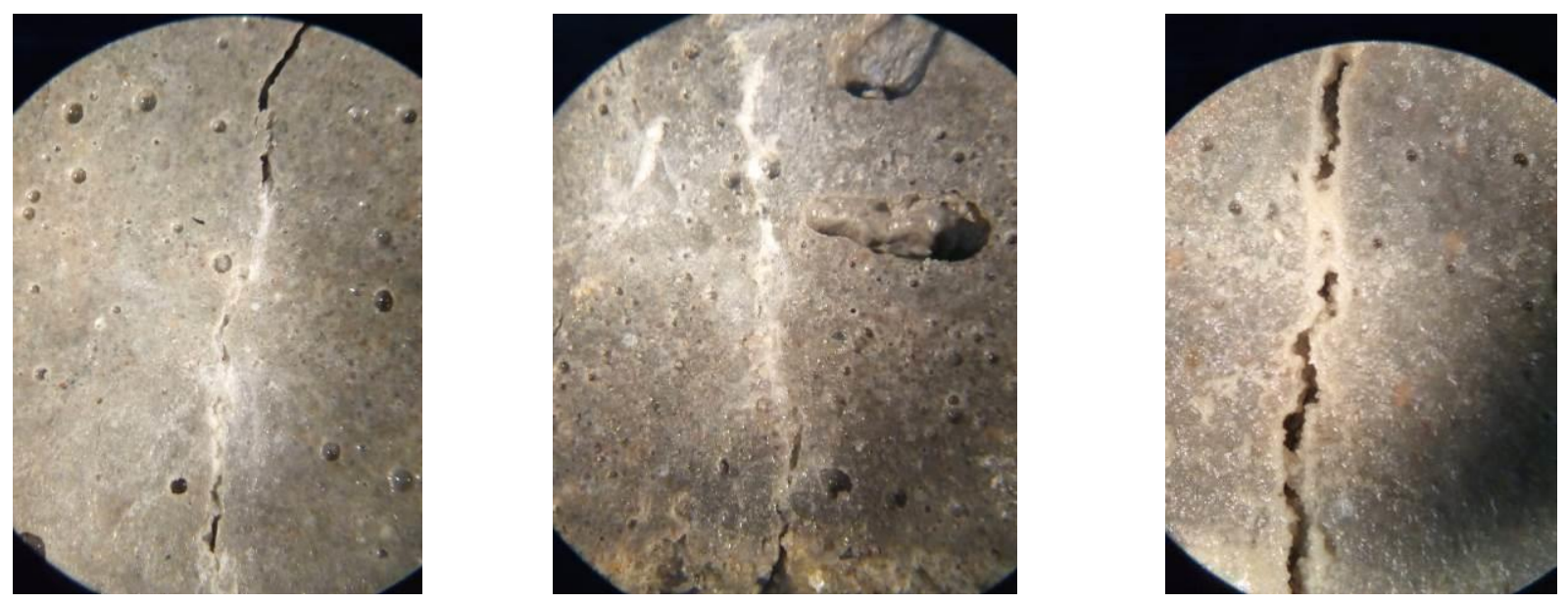

Fonte: Acervo do autor.

Figura 4 - Análise microscópica da autocicatrização nas amostras T10 

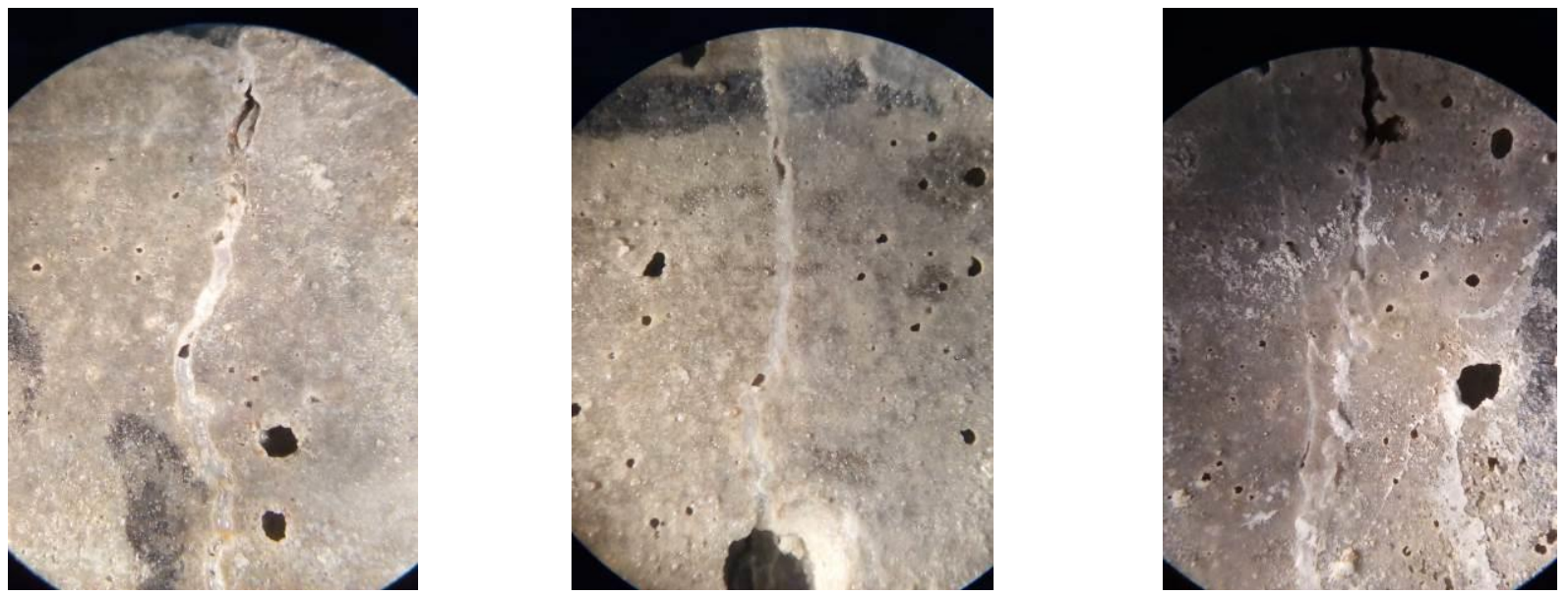

Fonte: Acervo do autor.

Figura 5 - Análise microscópica da autocicatrização nas amostras T20

Segundo Bianchi (2018), para potencializar a cicatrização das fissuras é interessante utilizar de métodos que minimizem o consumo de cimento nas idades inicias. Dentre algumas soluções mais eficientes encontra-se o uso de materiais nos quais a sílica está presente.

Formia et al. (2016) avaliou em experimentos a utilização de diferentes materiais cicatrizantes em estruturas de matriz cimentícia, dentre eles, o silicato de sódio e de potássio. Os valores encontrados em relação a recuperação da estrutura e na regeneração da resistência foram surpreendentes, principalmente quando utilizado o silicato de sódio. Huang e Ye (2011) confirma o citado anteriormente quando conclui que a concentração de silicato de sódio presente nas amostras é o fator principal que influencia a eficiência de cicatrização.

Neste estudo, pode-se observar que, como esperado, as amostras contendo maior adição de perlita, logo maior concentração de silicato de sódio neutro, obtiveram melhor desempenho em sua autocicatrização. Isso pode ser afirmado pois houve selagem da fissura completamente em maiores extensões. A autocicatrização também ocorre nos poros internos e externos da amostra possuindo grande potencial de aumento de durabilidade e recuperação das propriedades mecânicas ao longo de sua vida útil. A Figura 6 expressa quantitativamente a cicatrização de cada amostra através da proporção da área cicatrizada.

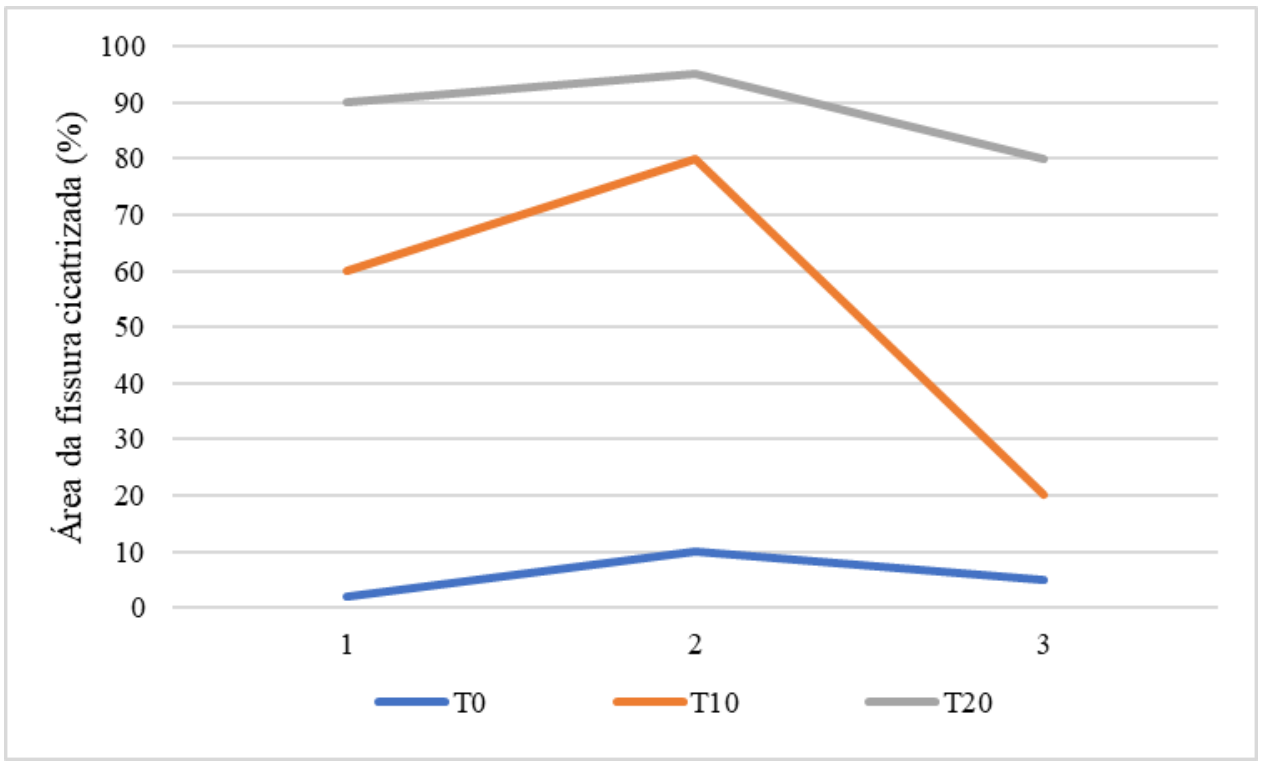

Fonte: Elaborado pelo autor.

Figura 6 - Resultado quantitativo de cicatrização das amostras 


\section{CONCLUSÕES}

No decorrer do estudo pode-se observar que:

1. A composição e o método utilizados demonstraram compatibilidade e eficiência com os princípios do concreto autocicatrizante, reparar de maneira autônoma suas fissuras;

2. A resistência a compressão axial aumentou proporcionalmente ao aumento de adição de perlita;

3. Mesmo mantendo um padrão de fissuras nas três diferentes misturas a amostra T20 apresentou a maior proporção de cicatrização das fissuras em uma mesma idade.

\section{REFERÊNCIAS}

ASSOCIAÇÃO BRASILEIRA DE NORMAS TÉCNICAS. NBR 12142: Concreto - Determinação da resistência à tração na flexão de corpos de prova prismáticos. Rio de Janeiro, 2010.

ASSOCIAÇÃO BRASILEIRA DE NORMAS TÉCNICAS. NBR 5738: Procedimento para moldagem e cura de corpos de prova. Rio de Janeiro, 2003.

ASSOCIAÇÃO BRASILEIRA DE NORMAS TÉCNICAS. NBR 5739: Ensaios de compressão de corpos de prova cilíndricos. Rio de Janeiro, 2018.

ASSOCIAÇÃO BRASILEIRA DE NORMAS TÉCNICAS. NBR 6118: Projeto de estruturas de concreto Procedimentos. Rio de Janeiro, 2014.

ASSOCIAÇÃO BRASILEIRA DE NORMAS TÉCNICAS. NBR NM 248: Agregados - Determinação da composição granulométrica. Rio de Janeiro, 2003.

ASSOCIAÇÃO BRASILEIRA DE NORMAS TÉCNICAS. NBR NM 52: Agregado miúdo - Determinação da massa específica e massa específica aparente. Rio de Janeiro, 2009.

ASSOCIAÇÃO BRASILEIRA DE NORMAS TÉCNICAS. NBR NM 53: Agregado graúdo - Determinação da massa específica, massa específica aparente e absorção de água. Rio de Janeiro, 2009.

BIANCHIN, F. H. Avaliação da autocicatrização em concretos produzidos com aditivo cristalizante e fissurados nas primeiras idades. 2018. 102 f. Trabalho de Conclusão de Curso (Graduação) - Universidade Federal do Rio Grande do Sul, Departamento de Engenharia Civil. Porto Alegre, RS, Brasil, 2018.

CAPPELlESSO, V. G. Avaliação da autocicatrização de fissuras em concretos com diferentes cimentos. Dissertação (Mestrado em Engenharia) - Universidade Federal do Rio Grande do Sul, Programa de Pós-graduação em Engenharia Civil: Construção e Infraestrutura. Porto Alegre, RS, Brasil, 2018.

ClaudinO, C. M. A.; GOMES, B. M. C.; NEVES, Y. T.; NASCIMENTO, M. V. Presença de bactérias no concreto: Uma análise da biodeterioração e bioregeneração. In: CONPAR - Conferência Nacional de Patologia e Recuperação de Estruturas, Recife, Pernambuco, 2017.

DE ARAUJO, C. E. S. B.; ABREU, B. G.; ÓRFÃO; R. B.; AMARANTE, M. S. Bioconcreto. Revista Diálogos Interdisciplinares, vol. 8, n. 2, 2019.

DOBROVOLSKI, M. E. G.; MUNHOZ, G. S.; NENEVÊ, B. L.; DIAS, R. L.; GODINHO, J. P.; MEDEIROS, M. H. F. Influência do silicato de sódio neutro na degradação de pastas de cimento Portland submetidas ao ataque por ácido sulfúrico. In: $4^{\circ}$ SPPC - Simpósio Paranaense de Patologia das Construções, Curitiba, Paraná, 2019.

FARAH, R. Concreto autocicatrizante com agregado regional. Revista Científica Semana Acadêmica. Fortaleza, ano MMXVII, Nº 000139, 2018.

FORMIA, A.; IRICO, S.; BERTOLA, F.; CANONICO, F.; ANTONACI, P.; PUGNO, N.M.; TUlliANI, J.M. Experimental analysis of self-healing cement-based materials incorporating extruded cementitious hollow tubes. Journal of Intelligent Materials Systems and Structures, vol. 27, issue 19, 2016. 
HUANG, H.; YE, G. Application of sodium silicate solution as self-healing agent in cementitious materials. In: Proceedings of International Conference on Advances in Construction Materials through Science and Engineering, Hong Kong, China, 2011.

JEDIDI, M.; BENJEDDOU, O.; SOUSSI, C. Effect of expanded perlite aggregate dosage on properties of lightweight concrete. Jordan Journal of Civil Engineering, vol. 9, n. 3, 2015.

KHONSARI, V.; ESLAMI, E; ANVARI, A. Effect of expanded perlite aggregate (EPA) on the mechanical behavior of lightweight concrete. In: 7th International Conference on Fracture Mechanics of Concrete and Concrete Structures, Jeju, South Korea, 2010.

MOREIRA, M. M. Efeito do aditivo redutor de permeabilidade em concretos com diferentes tipos de cimento Portland: contribuição aos processos de autocicatrização. Dissertação (Mestrado em Estruturas e Construção Civil) Universidade de Brasília. Brasília, DF, Brasil, 2017.

SBARDELOTTO, E. K.; ZITO, A. N.; MENDES, A. R.; SILVA, A. P. P. S.; DIAS, R. V. Relação entre tecnologias de concretos autocicatrizantes e aspectos de sustentabilidade. In: XI EPCC - Encontro Internacional de Produção Científica, Maringá, Paraná, 2019.

VENQUIARUTO, S. D. Influência da microfissuração causada nas primeiras idades na durabilidade de concretos ao longo do tempo (self-healing). Tese (Doutorado em Construção Civil) - Universidade Federal do Estado do Rio Grande do Sul, Programa de Pós-Graduação em Engenharia Civil. Porto Alegre, RS, Brasil, 2017.

VERGARA, M. L.; FARGAllO, A. P.; ARCAS, J. P.; TRIVIÑO, G. C.; NAVERRETE, J. P. Influence of Granulometry on Thermal and Mechanical Properties of Cement Mortars Containing Expanded Perlite as a Lightweight Aggregate. MDPI Journal - materials, vol. 12, issue 23, 2019.

VIEIRA, G. L. Influência da microfissuração causada por carregamento precoce nas propriedades mecânicas de concretos produzidos com diferentes tipos de cimento. Tese (Doutorado em Engenharia). Universidade Federal do Rio Grande do Sul, Programa de Pós-graduação em Engenharia Civil. Porto Alegre, RS, Brasil, 2008. 